\title{
Higher Order Thinking Questions in Teaching Reading in a Private Primary School ${ }^{1}$
}

\author{
Rosalinda Mintre \\ rosalinda.mintre@xinzhong.sch.id \\ Xin Zhong Primary School \\ $\&$ \\ Anita Lie \\ anita@ukwms.ac.id \\ English Language Teaching, Graduate School \\ Widya Mandala Catholic University Surabaya \\ Indonesia
}

\begin{abstract}
Critical thinking skill is one of the twenty-first century skills which need to be fostered in class. English teachers could integrate their lessons with critical thinking skills by eliciting students' responses through Higher Order Thinking (HOT) questions in teaching reading. This study attempts to see the questioning strategies used in Grade 5 reading classes in a private primary school in Surabaya by thoroughly looking at (1) the structure of the teacher's questions, (2) the types of the teacher's questions, and (3) the students' responses. The New Bloom's taxonomy was used as the main basis of the study to classify the types of questions and the students' responses. With four class observations, four teacher's interviews and two students' focus group discussions, this study found that most of the questions used in the classroom were HOT questions. The data showed that $65.15 \%$ of the total of 66 questions used by the teacher in the classroom were HOT questions, dominated by New Bloom's 'analyze' questions with $37.88 \%$ of the total questions. HOT questions were mostly addressed during the whilst-instructional activities, and the answers to these questions were of various forms: oral answers, dramatizations and presentations. The students' responses reached the same thinking level as the questions. The teacher, moreover, was pleased with his students' responses even though he sometimes needed to rephrase his questions in order to obtain students' appropriate responses.
\end{abstract}

Keywords: critical thinking, higher order thinking skills, reading

\section{Introduction}

To equip learners with critical thinking and problem-solving skills in facing the $21^{\text {st }}$ century, schools need to cover these four elements proposed by Stobie (2013): ways of thinking, ways of working, tools for working, and skills for living in the world. Critical thinking itself comprises: (1) awareness of a set of interrelated critical questions, (2) ability to ask and answer critical questions at appropriate times, and (3) the desire to actively use the critical questions (Browne \& Keeley, 2007, p. 2).

In English teaching, learners' critical thinking and problem-solving skills can be fostered through the use of higher order thinking or HOT questions in teaching reading. Meaningful reading requires at least four components of knowledge including knowledge of words, knowledge of language, background knowledge of the

\footnotetext{
${ }^{1}$ This article has been accepted to be published in Beyond Words Vol. 8 No. 1. May 2020

DOI: https://doi.org/10.33508/bw.v8i1.2092
} 
reader 'and the context knowledge of the reading (Morrow, 2005 as quoted by Sunggingwati \& Nguyen, 2013, p. 81). In addition, it needs to integrate cultural and ethic differences (Sunggingwati \& Nguyen, 2013). To help learners develop their critical reading, teachers can ask different kinds of questions. Furthermore, teachers' questioning strategies in reading can trigger students to think more critically and understand the text more deeply (Jacobsen, et al., 1999; Kligner, et al., 2007, as cited by Sunggingwati \& Nguyen, 2013). To this point, Renaud \& Murray (2007, p. 319) state that the frequency of higher-order questions can be a valid process indicator as it is related to gains in students' critical thinking skills.

Bapan (2016) made a research on questioning strategies in a class consisting of 25 seventh graders in a junior high school. He focused on these four segments: (1) the types of questions, (2) the frequency of the questions types, (3) the reasons teacher addressed the high frequency questions and (4) learners' responses to the teacher's questions. His study revealed that referential questions were more frequently asked than display questions. During the interview, the teacher asserted that referential questions elicit more information and build interaction with the students, which made them favorable to be used by him. He added that referential questions livened up his teaching. Referential questions, on the other hand, also trigger students' more complex responses.

Sunggiwati \& Nguyen (2013) conducted a study on questioning strategies used by the teachers in three senior secondary state schools in Samarinda, Indonesia. They observed the practices of the teachers in teaching reading in those schools. This study found out that the teachers relied on the questions in textbooks for teaching reading; as a result, they faced some challenges in generating high-level questions and required assistance in formulating HOT questions (Sunggingwati \& Nguyen, 2013, p. 80).

Another research on questioning strategies was done by Ndun (2012). Ndun observed and analyzed the questioning strategies used by the junior high school teachers in their classroom in Soe, South Central Timor, Indonesia. This study was based on these three research questions: (1) What types of questions do the teachers tend to use in the daily practices of teaching in the EFL classroom?, (2) What are the functions of the questions asked by the teacher?, and (3) How do the students respond to the questions?. This study revealed that the teachers mostly used display questions or lower order thinking questions (92\%) and less referential questions or higher order thinking questions $(8 \%)$.

Tamah (2003) initiated a research about questioning strategies by investigating the inquiry process in EFL classes. Her study revealed that display questions were frequently used; on the other hand, referential and comprehension questions were the least.

The Indonesian Ministry of Education and Culture (MOEC) is aware of the importance of incorporating higher order thinking skills (HOTS) in education. As HOTS items are inserted in the national exam, Indonesian MOEC requires teachers to integrate critical thinking in their teaching (Indonesian Ministry of Education and Culture, 2019). Consequently, teacher's competence in enhancing their students' critical thinking through effective questioning strategies becomes crucial.

The present study, therefore, aims to discover more on the implementation of the teacher's questioning strategies in reading classes in a private primary school in Surabaya. In addition, this study would also like to analyze whether the teacher adequately used HOT questions in his reading classes. 


\section{Critical Thinking}

There are various definitions of critical thinking proposed by experts. Masduqi (2011) believes that critical thinking means observing, experiencing, reflecting, reasoning or communicating to believe or act.

Larsson (2017) conducted an empirical study regarding critical thinking topic. His research limited critical thinking in four qualities of a person:

1. Identify conclusions, reasons and assumptions

2. Judge the quality of an argument, including the acceptability of its reasons, assumptions and evidence

3. Develop and defend a position on an issue

4. Draw conclusions when warranted, but with caution

Bailin, Case, Coombs, \& Daniels (1999) argue that critical thinkers should have qualities which include (1) respect for reasons and truth, (2) respect for high-quality products and performances, (3) an inquiring attitude, (4) open-mindedness, (5) fairmindedness, (6) independent-mindedness, (7) respect for others in group inquiry and deliberation, (8) respect for legitimate intellectual authority, and (9) an intellectual work-ethic.

In helping students to be critical thinkers, Brown (2001) argues that teachers should apply these four principles to fully respect the values and beliefs of the students: (1) Allow students to express themselves openly - be sensitive to power relationships, encourage candid expression; (2) Genuinely respect students' points of view - seek to understand their cherished beliefs and traditions; (3) Encourage both/many sides of an issue--welcome all seriously offered statements, opinions, and beliefs; and (4) don't force students to think just like you delay or withhold your own opinion. Moreover, teachers should involve these three components in their teaching: (1) students' engagement in tasks which require reasoned judgement or assessment, (2) intellectual resources for tasks and (3) critical thinking environment which values and encourages students to be involved in critical discussions (Bailin, Case, Coombs, \& Daniels, 1999).

Higher Order Thinking is defined in three categories transfer, critical thinking and problem solving (Brookhart, 2010: 3). This study will be more specific on critical thinking. Critical thinking is reasonable, reflective thinking that is focused on deciding what to believe or do (Norris \& Ennis, 1989 as cited by Brookhart, 2010). Brookhart (2010) further states that students can apply wise judgment or produce a reasoned critique. The characteristics of critical thinking, according to Barahal (2008, as cited by Brookhart, 2010) are triggering reasoning, questioning and investigating, observing and describing, comparing and connecting, finding complexity, and exploring viewpoints. The purpose of critical thinking is to equip learners with the ability to reason, reflect, and make sound decisions without being assisted by teachers or assignments (Brookhart, 2010: 6).

\section{The New Bloom's Taxonomy}

Reading is one of the receptive skills needed in language acquisition. Furthermore, reading is much emphasized in schools in Indonesia since it enables students to develop their comprehension skills. However, reading comprehension skill is surely not enough to prepare students for the challenges in the future; other skills are needed, and one of which is critical thinking. 
There are many implementations of critical thinking skills in teaching reading, one of which is by using questioning strategies. Critical thinking skills should be taught by using questioning techniques in the classroom since they help students to comprehend the text. In line with this, Duron \& Waugh (2006) believe that questions can be used to stimulate interaction between teacher and learner and to challenge the learner to defend his or her position, (i.e., to think critically). Teachers, therefore, should consider the purpose of each question and then develop the appropriate level and type of question to accomplish the goal (Duron \& Waugh, 2006).

There are some taxonomies that are organized based on the cognitive processes; this study uses the new version of Bloom's Taxonomy. Bloom's Taxonomy is almost 60 years old, and it has been redefined. The new version of Bloom's taxonomy is concerned about the criticisms delivered on the previous Bloom's taxonomy (Wilson, 2016).

There are six levels of the New Bloom's Taxonomy (Anderson and Krathwohl, 2001 as cited by Brookhart, 2010: 40-41):

Remember. This level involves recognizing or recalling facts and concepts. The example of the question is "Where and when did the story take place?".

Understand. This level involves basic comprehension, understood in light of newer theories of learning that emphasize students constructing their own meaning. The example of the question is "Can you list the five major events in the story in the correct order?"

Apply. Apply refers to executing or implementing a procedure to solve a problem. The example of the question is "If you were in a problem situation like one in the book, how would you have acted?"
Analyze. Analyze refers to breaking information into its parts, and determining how the parts are related to each other and to the overall whole. The example of the question is "What motive did the main character have for behaving in the way they did?"

Evaluate. Evaluate means judging the value of material and methods for given purposes, based on criteria. The example of the question is "Do you agree with the actions of the main character?"

Create. Create refers to putting disparate elements together to form a new whole, or reorganizing existing elements to build a new structure. The example of the question is "If you could only save one character from the book in the event of a disaster, which one would it be and why?"

\section{Questions in Teaching Reading}

Questioning strategies in the classroom are needed in order to create an active learning atmosphere. An active learning class enforces students to think about what they are doing (Bonwell and Eison, 1991 cited by Duron \& Waugh, 2006). Fink (2003 in Duron $\&$ Waugh, 2006) mentions that students learn more and retain knowledge longer if they acquire it in an active rather than passive manner. To create an active learning class, interactions in class, especially between teachers and students, are highly needed. By so doing, teachers' talk can be minimized in the classroom.

Interactions between teachers and students can be triggered through questioning strategies in class. Brown and Edmonson (cited in Çakmak, 2009; Hamiloglu \& Temiz, 2012) mentions the following goals of teacher's questions:

a. to arouse interest and curiosity concerning a topic,

b. to focus attention on a particular issue or concept, 
c. to develop an active approach to learning,

d. to stimulate pupils to ask questions to themselves and others,

e. to diagnose specific difficulties inhibiting pupil learning,

f. to express a genuine interest in the ideas and feelings of the pupils, and

g. to provide an opportunity for pupils to assimilate and reflect upon information.

Besides, as quoted in Sunggingwati \& Nguyen (2013), questioning strategies are

\section{Method}

This is a qualitative study specified in a case study. It investigated how oral questions in reading classes were addressed by the teacher.

This study was conducted in a private primary school in Surabaya, Indonesia. The participants of this study were an English teacher teaching in Grade 5 and his twentyfour Grade 5 students. Fig. 1. below describes the flow of the study:

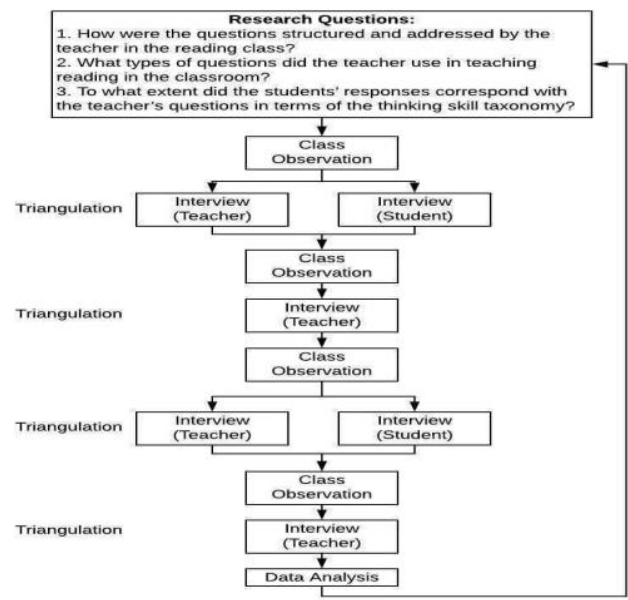

Fig. 1. The framework of the Study

\section{Instruments for Data Collection}

Prior to the observation of the researched class, a rubric and a classroom observation protocol were prepared. The Bloom's revised taxonomy rubric was used to classify the questions in their correct category; meanwhile, the classroom observation protocol served as an aid to note applied (a) to make readers aware of the important points of a reading passage (Day \& Bamford, 1998; Vandermeij, 1994), (b) to check comprehension (Gerot, 2000; Nutall, 1982), (c) to extend the topic, (d) to link the passage to previous knowledge and experience to improve comprehension (Handsfield \& Jienez, 2008; Walker, 2000), and (e) to serve as assessment about whether students understand what they have been taught (Kintsch, 2005).

the objectives of the lesson, materials used and flow of the class. During the classroom observation, both rubric and classroom observation protocol were used, accompanied by a field note which was used to record the students' responses towards the oral questions given by the teacher. Besides, the lesson was cam-recorded and audiorecorded.

Following the class observation, a semistructured interview with the teacher was conducted to clarify some points of the teaching. Afterwards, a focus group discussion was conducted with randomlyselected five students in order to triangulate the existing data. The focus group discussions were held after the first and third classroom observations. These stages were repeated four times since there were four observations conducted in this study.

\section{Data Source and Unit of Analysis}

Using Bloom's revised taxonomy as the base, this study was expected to discover the types of questions used, which were then classified as lower order thinking (or LOT) questions and higher order thinking (or HOT) questions, the delivery of the questions and the students' responses towards the teacher's questions. The research data were collected from the classroom observation, teacher's interviews and students' interviews. The 
class observation was conducted four times in three months in order to collect the data of the oral questions used by the teacher in teaching reading. The oral questions were then categorized into two: LOT questions (Remember, Understand and Apply) and HOT questions (Analyze, Evaluate and Create). The structure of the questions' delivery was noted as well as the students' responses towards the questions.

\section{Findings and Discussion}

The data analysis above is discussed in three main points: (1) the flow of the lesson, (2) the types of questions used and (3) the structure of questions used.

\section{The Flow of the Lesson}

Interactions between teacher and students were clearly seen. From the beginning to the end of each class meeting, the teacher actively gave questions to his students.

The teacher always started his reading lesson by reviewing the previous lesson and pre-teaching the related vocabulary. During the first and second observations, the teacher unlocked the vocabulary through games; during the third and fourth observations however, the teacher unlocked the meaning of the sentences which were taken from the texts. In the fourth observation, the teacher also assigned the students to work in groups to interpret the lines taken from a poem. The teacher set the cornerstone before building students' comprehension in the reading texts.

In fact, the fourth observed class was quite different from the other class meetings since the teacher provided an introduction in which he asked the students to imagine what they were going to be in the future. The teacher even put his students under his suggestive influence by giving a monologue asking them to think about their future. During the interview, the teacher asserted that the monologue helped him to give a
The unit of analysis in this study is sentences in the form of questions uttered by the teacher and responses from the students to the teacher's questions. The questions related to the reading text were analyzed in this study; meanwhile, the other questions which had no relation with the reading text were ignored. Students' responses were scrutinized according to the wait time and the expected answer.

smooth transition from the preliminary to the main lesson.

There are various forms of reading activities presented in these four observations. In the first and fourth observations, the teacher conducted a reading-aloud activity whereas in the second and third observations, the students were just reading the text silently. The teacher presented himself as the model of a reader reading the text aloud during the first and fourth observations. After that, his students were also asked to read the text aloud.

Next, the teacher asked the students some oral questions, ranging from LOT levels to HOT levels. He also assigned the students to work in groups to answer certain HOT questions in the first and second observations. Interestingly, the students were allowed to answer the HOT questions in various forms: oral answers, presentation and dramatization. It was quite different from the third and fourth observations in which the teacher preferred to have a classroom discussion. In addition, in the fourth observation, he asked the students to sing the poem.

Most of the students seemed to be enthusiastic during the lesson. In the first Focus Group Discussion (FGD), they even stated that the teacher's lesson would always be the most fun and exciting lesson in school. Besides, fewer students were sleepy and 
drowsy during the observation. However, the students admitted that the teacher rarely addressed questions to them during reading. The result was quite consistent with the second FGD which implies that the teacher sometimes asked questions to the students during reading.

\section{The Structure of the Questions Used}

Based on the four observations undertaken, the reading activities mostly started with HOT questions addressed by the teacher. They served as triggering questions which activated the students' background knowledge so that they could be engaged with the reading. The following questions exemplify the HOT questions used in the preinstructional activities:

1. Is it good to brag the possessions that we have? Why or why not?

2. Have you been a victim of these gossipers or have you been gossipers sometimes?

3. Is it good to gossip really to one's life? Everybody?

However, during the second observed class, the teacher began the pre-reading activities by asking two lower order thinking questions, that is definition questions. The following lower order thinking questions were addressed in the second observation:

1. (Teacher showed a definition on the slide and asked the students to write the answers on the small boards.) Definition: it refers to the timely issues or current events that we usually see and hear on television and radio respectively. (This implies that the teacher asked a question "What does the definition refer to?")

2. (Teacher showed a description on the slide and asked the students to write the answers on the small boards.) Definition: a complete name of Surabaya mayor who was the reason why the city was shortlisted in the Guangzhou International Award last year for having a good waste management system. (This implies that the teacher asked a question "Who is the mayor of Surabaya?")

During the whilst-instructional activities, the teacher mostly addressed questions from LOT levels to HOT levels. However, he might go back and forth among the levels in higher order thinking questions. For example, during the third observation, the teacher addressed lower order thinking questions ranging from two 'remember' questions and two 'understand' questions. Subsequently, he went deeper to higher order thinking, beginning with six 'analyze' questions and one 'evaluate' question. Nevertheless, the teacher went down to 'analyze', then went up to 'evaluate'. Afterwards, he went back to 'apply', rose to 'create' and moved backward to 'evaluate'.

As post-instructional activities, during the first and fourth observed classes, the teacher inquired higher order thinking questions to end the reading session; on the other hand, in the second and third observed classes, he went on with grammar lessons.

During the post-interview, the teacher asserted that he planned the questions ahead of time. There are several reasons: (1) he could refine his questions before being asked to the students, and (2) he could set the expected answers from his students. Along with the flow of his teaching, he might create more questions, either to help the students answer the main questions or to address more challenging questions to the students.

\section{The Types of Questions Used}

From these four observations, it can be concluded that the HOT questions were the most frequently used in the classroom. They dominated the questions used by $65.15 \%$. The Bloom's analyze questions contributed the most, addressed twenty-five times out of sixty-six. On the other hand, the LOT questions, despite being less frequently used, 
were responsible for $34.85 \%$ of the total number of the questions used in these four observations. The table below concludes the findings.

Table 1

The Percentages of the Questions classified in the New Bloom's Taxonomy

\begin{tabular}{|c|c|c|c|c|c|}
\hline $\begin{array}{l}\text { Question } \\
\text { Level }\end{array}$ & $\begin{array}{l}\text { Total } \\
\text { Questions }\end{array}$ & Percentage & $\begin{array}{c}\text { The New Bloom's } \\
\text { Taxonomy } \\
\text { Classification }\end{array}$ & $\begin{array}{l}\text { Total } \\
\text { Questions }\end{array}$ & Percentage \\
\hline \multirow{3}{*}{$\begin{array}{l}\text { Lower Order } \\
\text { Thinking } \\
\text { questions }\end{array}$} & \multirow{3}{*}{23} & \multirow{3}{*}{$34.85 \%$} & Remember & 10 & $15.15 \%$ \\
\hline & & & Understand & 10 & $15.15 \%$ \\
\hline & & & Apply & 3 & $4.55 \%$ \\
\hline \multirow{3}{*}{$\begin{array}{l}\text { Higher } \\
\text { Order } \\
\text { Thinking } \\
\text { questions }\end{array}$} & \multirow{3}{*}{43} & \multirow{3}{*}{$65.15 \%$} & Analyze & 25 & $37.88 \%$ \\
\hline & & & Evaluate & 14 & $21.21 \%$ \\
\hline & & & Create & 4 & $6.06 \%$ \\
\hline TOTAL & 66 & $100.00 \%$ & TOTAL & 66 & $100.00 \%$ \\
\hline
\end{tabular}

Table 2 below shows the numbers of the LOT and HOT questions based on the stages of teaching. It displays the stage when the HOT questions were addressed the most; it was during whilst-instructional activities. Besides, it illustrates that the least number of the HOT questions were addressed in the last stage: post-instructional activities.

Table 2

The Percentages of HOT and LOT Questions Based on the Teaching Stages

\begin{tabular}{|c|c|c|c|c|c|c|c|c|c|c|c|c|}
\hline \multirow{2}{*}{ Stage } & \multicolumn{2}{|c|}{ Obs 1} & \multicolumn{2}{|c|}{ Obs 2} & \multicolumn{2}{|c|}{ Obs 3} & \multicolumn{2}{|c|}{ Obs 4} & \multicolumn{4}{|c|}{ Total } \\
\hline & LOT & HOT & LOT & HOT & LOT & HOT & LOT & HOT & LOT & HOT & LOT & HOT \\
\hline $\begin{array}{c}\text { Pre- } \\
\text { Instructional } \\
\text { Activities }\end{array}$ & 0 & 1 & 2 & 0 & 4 & 4 & 0 & 6 & 6 & 11 & $9.09 \%$ & $16.67 \%$ \\
\hline $\begin{array}{c}\text { Whilst- } \\
\text { Instructional } \\
\text { Activities }\end{array}$ & 2 & 3 & 4 & 3 & 5 & 17 & 5 & 7 & 16 & 30 & $24.24 \%$ & $45.45 \%$ \\
\hline $\begin{array}{c}\text { Post- } \\
\text { Instructional } \\
\text { Activities } \\
\end{array}$ & 1 & 1 & & & & & 0 & 1 & 1 & 2 & $1.52 \%$ & $3.03 \%$ \\
\hline TOTAL & 3 & 5 & 6 & 3 & 9 & 21 & 5 & 14 & 23 & 43 & $34.85 \%$ & $65.15 \%$ \\
\hline
\end{tabular}

The result of the study is in line with the previous research conducted by Bapan (2016). Based on the three observations conducted, he found that referential questions and display questions were used as the questioning strategies; nevertheless, referential questions were the most frequently addressed. Display questions, 
classified as LOT, are inquiries structured to test learner's understanding of the language structures and items; meanwhile, referential questions, known as HOT, are used to elicit students' critical opinion, explanation and clarification towards the content of the language (Bapan, 2016). Besides, he also claimed that the teacher posed referential questions to dig more information and build lively interaction with the students, which is similar to the teacher's perspective in this present study.

The findings of the present study are entirely different from Sunggiwati \& Ngunyen's study (2013). In Sunggiwati \& Nguyen's study, the teacher relied mostly on the questions given in the reading textbook. It was found that among 75 questions found in total, with Raphael's taxonomy, 71 Right There questions, 2 Think and Search questions and 2 Author and Me questions were discovered. Converting them to the New Bloom's taxonomy, Right There and Think and Search questions belong to LOT questions whereas Author and Me and On My Own questions represent HOT questions. Thus, 73 questions or $97.4 \%$ of the total questions were LOT questions while, 2 questions or $2.7 \%$ of the total questions were HOT questions.

The result clearly implies that the teacher mostly uses HOT questions in his teaching. In the interview, the teacher explained that his students were quite advanced; therefore, LOT questions would be boring since the answers are obvious. Moreover, HOT questions are more engaging than LOT questions.

In order to answer HOT questions, the teacher frequently assigned the students to work in groups. There are several reasons asserted by the teacher: (1) group work makes students enjoy learning because every member is involved in the discussion; (2) group work fosters collaborative skills since the students have to conclude and come to the same agreement and conclusion about the activity; (3) group work facilitates high achievers to assist the low achievers so that they can develop themselves; and (4) group work can cover each other's flaw.

\section{The Students' Responses}

The research findings show that the answers of the HOT questions were mostly in line with the thinking skill taxonomy. Besides, the students' answers varied. Some HOT questions required the students to answer them orally whereas certain quite challenging HOT questions were answered in groups through performance. Overall, the teacher was satisfied with his students' responses.

Based on the qualities of critical thinkers mentioned by Bailin et al. (1999), the four observations show that the students demonstrated "respect for reasons and truth", "respect for high-quality products and performances", “open-mindedness", "fairminded-ness", "independent-mindedness", "respect for others in group inquiry and deliberation" and "respect for legitimate intellectual authority". In the four class observations, hardly any students undermined other students' answers unless the answer was irrelevant and out of context. Mostly, they were receptive to new ideas and thoughts about the questions. The same way happened in group work activities. No conflict was found during their group discussion or their group presentation.

However, almost no students asked questions to the teacher. The quality of "an inquiring attitude" as stated by Bailin, Case, Coombs, \& Daniels (1999) was hardly seen in the observation. There were some possible causes: (1) the students were afraid if their questions might have challenged the teacher and resulted in the group point deduction, (2) 
the students did not understand the question completely, (3) the wait-time given by the teacher was too short for the students to compose questions, and (4) the students were not conditioned to ask questions to the authority to be regarded as well-mannered students in the Indonesian culture.

Looking back at the characteristics of critical thinking proposed by Barahal (2008) as cited by Brookhart (2010: 4) namely triggering reasoning, questioning and investigating, observing and describing, comparing and connecting, finding complexity, and exploring viewpoints, students in the class meetings relied hard on the questions of the teacher in order to be active. They reasoned, investigated and described according to the questions presented by the teacher.

It is still understandable that the fifth graders did not show all the qualities that critical thinkers should have since they were still at the concrete operational stage where they could give logical reasoning to an issue as long as it was applied to concrete examples (Piaget, 1952 as cited by Santrock, 2011 p. 288). It was not surprising that the students could give elaborate answers during the third observation when they were asked about their life experience against bullying. The cases presented on that day were concrete issues they commonly faced at school.

\section{Conclusion and Suggestions}

English teachers need to master questioning skills. Questioning strategies are required not only to help students develop their critical thinking skills but also to liven up the atmosphere of the teaching and learning process. In order to apply the questioning strategies smoothly, teachers need to prepare the questions ahead of time. Some workshops or training are also required

for English teachers to sharpen their questioning strategies.

This study also found out that students hardly ever gave questions to the teacher. This might happen because of their insecure feeling. The precise reasons why students lack questioning skills, however, need to be researched further. It can be an interesting topic for future researchers.

(C) Mintre, Rosalinda \& Lie, Anita. (2020).

Rosalinda Mintre, M.Pd. is an English teacher at Xin Zhong Primary School, Surabaya. She graduated from the English Department of Widya Mandala Catholic University Surabaya in 2016 and completed her Master's degree in ELT from the Graduate School of the same University in 2019. Her research interest is on developing students' HOT skills.

Prof. Anita Lie, Ed.D. is professor at Widya Mandala Catholic University, Surabaya, Indonesia. Her areas of research are teacher professional development, English education and heritage language learning. She was Ms. Mintre's Master Thesis Advisor, and continued co-authoring the thesis into this article.

\section{References}

Bailin, S., Case, R., Coombs, J. R., \& Daniels, L. B. (1999). Conceptualizing critical thinking. Journal of curriculum studies 31, 285-302.

Bapan, D. N. (2016). Teacher Questions in Junior High School Classroom.
Surabaya: English Education Department Graduate School Widya Mandala Catholic University.

Barahal, S. L. (2008). Thinking about thinking. Phi Delta Kappan 90.4, 298302. 
Brookhart, S. M. (2010). How to Assess Higher Order Thinking Skills in Your Classroom. USA: ASCD.

Brown, H. D. (2001). Teaching by Principles An Interactive Approach to Language Pedagogy. New York: Pearson Education.

Browne, M. N., \& Keeley, S. M. (2007). Asking the Right Questions: A Guide to Critical Thinking. New Jersey: Pearson Education.

Duron, R., \& Waugh, B. L. (2006). Critical Thinking Framework for Any Discipline. International Journal of Teaching and Learning in Higher Education, 160-166.

Hamiloglu, K., \& Temiz, G. (2012). The Impact of Teacher Questions on Student Learning in EFL. Journal of Educational and Instructional Studies in the world, 1-8.

Indonesian Ministry of Education and Culture. (2014). Konsep dan Implementasi Kurikulum 2013. Paparan Wakil Pendidikan dan Kebudayan R.I Bidang Pendidikan (p. 118). Jakarta: Indonesian Ministry of Education and Culture.

Indonesian Ministry of Education and Culture. (2019, April 22). Ujian Nasional. Retrieved from BSNP: http://bsnpindonesia.org/category/uasbn-dan-un/

Larsson, K. (2017). Understanding and Teaching Critical Thinking - A New Approach. International Journal of Educational Research 84, 32-42.

Masduqi, H. (2011). Critical Thinking Skills and Meaning in English Language Teaching. TEFLIN, 185-200.
Ndun, L. N. (2012). Teachers' Questions in a Junior High School English Classroom. Yogyakarta: The Graduate Program, English Language Studies, Sanata Dharma University.

Papafragou, A., Li, P., Choi, Y., \& Han, C.h. (2007). Evidentiality in language and cognition. Cognition 103, 253-299.

Renaud, R. D., \& Murray, H. G. (2007). The Validity of Higher-Order Questions as a Process Indicator of Educational Quality. Research in Higher Education, 319-350.

Santrock, J. W. (2011). Life-Span Development Thirteenth Edition. New York: McGraw Hill.

Stobie, T. (2013). Implementing the Curriculum with Cambridge: A Guide for School Leaders. London: Cambridge International Examinations. Retrieved from www. cie. org. uk/images/134557implementing-the-curriculum-withcambridge. pdf

Sunggingwati, D., \& Nguyen, H. T. (2013). Teachers' Questioning in Reading Lessons: A Case Study in Indonesia. Electronic Journal of Foreign Language Teaching, 80-95.

Tamah, S. M. (2003). Teacher Questions in EFL Classes. Seameo Regional Language Centre Singapore.

Wilson, L. O. (2016). Anderson and Krathwohl - Bloom's Taxonomy Revised. Retrieved from The Second Principle: https://thesecondprinciple.com/teaching -essentials/beyond-bloom-cognitivetaxonomy-revised/ 